\title{
Oxidative stress-mediated mitochondrial dysfunction facilitates mesenchymal stem cell senescence in ankylosing spondylitis
}

Guiwen Ye ${ }^{1}$, Zhongyu Xie ${ }^{2}$, Huiqiong Zeng ${ }^{3}$, Peng Wang ${ }^{2}$, Jinteng Li ${ }^{2}$, Guan Zheng ${ }^{2}$, Shan Wang ${ }^{4}$, Qian Cao ${ }^{4}$, Ming Li ${ }^{1}$, Wenjie Liu', Shuizhong Cen', Zhaofeng $\mathrm{Li}^{1}$, Yanfeng $\mathrm{Wu}^{5}$, Zhizhong $\mathrm{Ye}^{3}$ and Huiyong Shen (1)

\begin{abstract}
Ankylosing spondylitis (AS) is a chronic inflammatory disease possessing a morbid serum microenvironment with enhanced oxidative stress. Long-term exposure to an oxidative environment usually results in cellular senescence alone with cellular dysfunction. Mesenchymal stem cells (MSCs) are a kind of stem cell possessing strong capabilities for immunoregulation, and senescent MSCs may increase inflammation and participate in AS pathogenesis. The objective of this study was to explore whether and how the oxidative serum environment of AS induces MSC senescence. Here, we found that AS serum facilitated senescence of MSCs in vitro, and articular tissues from AS patients exhibited higher expression levels of the cell cycle arrest-related proteins p53, p21 and p16. Importantly, the levels of advanced oxidative protein products (AOPPS), markers of oxidative stress, were increased in AS serum and positively correlated with the extent of MSC senescence induced by AS serum. Furthermore, MSCs cultured with AS serum showed decreased mitochondrial membrane potential and ATP production together with a reduced oxygen consumption rate. Finally, we discovered that AS serum-induced mitochondrial dysfunction resulted in elevated reactive oxygen species (ROS) in MSCs, and ROS inhibition successfully rescued MSCs from senescence. In conclusion, our data demonstrated that the oxidative serum environment of AS facilitated MSC senescence through inducing mitochondrial dysfunction and excessive ROS production. These results may help elucidate the pathogenesis of AS and provide potential targets for AS treatment.
\end{abstract}

\section{Introduction}

Ankylosing spondylitis (AS) is a chronic inflammatory disease with high morbidity and disability rates ${ }^{1}$. Chronic inflammation is a core feature of AS pathogenesis, but the associated mechanism is still unclear ${ }^{2}$. Alone with the chronic inflammation, AS patients always maintain a

Correspondence: Yanfeng Wu (wuyf@mail.sysu.edu.cn) or

Zhizhong Ye (yezhizhong@126.com) or Huiyong Shen (shenhuiy@mail.sysu. edu.cn)

'Department of Orthopedics, Sun Yat-Sen Memorial Hospital, Sun Yat-Sen University, Guangzhou 510120, P.R. China

2Department of Orthopedics, The Eighth Affiliated Hospital, Sun Yat-Sen University, Shenzhen 518033, P.R. China

Full list of author information is available at the end of the article

These authors contributed equally: Guiwen Ye, Zhongyu Xie, Huiqiong Zeng

Edited by $Y$. Wang morbid serum microenvironment, which has been reported to be abnormal in terms of inflammatory factor and oxidative stress levels ${ }^{3,4}$. Previously, we also found that the levels of advanced oxidative protein products (AOPPs), a marker of oxidative stress, were elevated in AS and positively correlated with disease activity ${ }^{5}$. However, whether and how the AS serum microenvironment participates in AS pathogenesis are still unknown.

Mesenchymal stem cells (MSCs) are a kind of stem cell that possesses strong capabilities for immunoregulation and trilineage differentiation ${ }^{6}$. MSCs dysfunction is tightly involved in multiple inflammatory diseases, such as osteoarthritis (OA), rheumatoid arthritis (RA), and $\mathrm{AS}^{7,8}$. Previous studies discovered that MSCs from AS patients exhibited multifunction disorder and MSCs from healthy

\section{(c) The Author(s) 2020}

(c) (i) Open Access This article is licensed under a Creative Commons Attribution 4.0 International License, which permits use, sharing, adaptation, distribution and reproduction in any medium or format, as long as you give appropriate credit to the original author(s) and the source, provide a link to the Creative Commons license, and indicate if changes were made. The images or other third party material in this article are included in the article's Creative Commons license, unless indicated otherwise in a credit line to the material. If material is not included in the article's Creative Commons license and your intended use is not permitted by statutory regulation or exceeds the permitted use, you will need to obtain permission directly from the copyright holder. To view a copy of this license, visit http://creativecommons.org/licenses/by/4.0/. 
donors (HDs) were effective for treating $\mathrm{AS}^{9-12}$, indicating a crucial role for MSCs dysfunction in AS pathogenesis. Thus, whether the morbid serum microenvironment of AS influences the functions of MSCs remains to be addressed. No relevant studies have been reported.

Cellular senescence is a cellular status characterized by irreversible cell cycle arrest in G0/G1, increased expression of cell cycle arrest-related proteins and high activity of senescence-associated $\beta$-galactosidase $(\mathrm{SA}-\beta \text {-gal })^{13}$. This state is usually induced by multiple replication and environmental stresses, such as an inflammatory condition or oxidative stress ${ }^{14}$. In addition, senescence always accompanies cellular dysfunction and may be involved in pathological processes ${ }^{15,16}$. It has been reported that senescent MSCs display a senescence-associated secretory phenotype (SASP), an impaired immunomodulatory function and aberrant differentiation capability ${ }^{17,18}$. Furthermore, in some autoimmune diseases such as systemic lupus erythematosus (SLE) ${ }^{19}$ and systemic sclerosis $(\mathrm{SSc})^{20}$, MSCs senescence is induced by the patient's serum and participates in disease development. However, whether a similar situation exists in AS remains unclear.

In this study, we determined the effect of the AS serum microenvironment on MSCs senescence and demonstrated that compared to serum from HDs, AS serum strikingly facilitated the senescence of MSCs. We further explored the underlying mechanism, and our data illustrated that the AOPPs in AS serum and the downstream mitochondrial dysfunction and excess ROS expression of MSCs were attributed to the senescence-promoting effect of the AS serum. Our findings suggest a role for the AS serum microenvironment in AS pathogenesis and provide several new targets for AS therapy.

\section{Materials and methods Ethical statement}

This study was approved by the Ethics Committee of Sun Yat-Sen Memorial Hospital, Sun Yat-Sen University, Guangzhou, China. Written informed consent about the experimental requirements and potential risks was provided by all subjects.

\section{Study subjects}

In this study, the population consisted of $20 \mathrm{HDs}$ and 20 AS patients. All the AS patients fulfilled the modified New York criteria ${ }^{21}$ and were in an active disease state (Bath Ankylosing Spondylitis Disease Activity Index (BASDAI) $\geq 4)^{22}$. The characteristics of the study subjects are presented in Supplemental Table 1.

\section{Isolation and culture of MSCs}

HDs were recruited, and MSCs were isolated and cultured as described previously ${ }^{23}$. Briefly, bone marrow puncture was performed, and MSCs were isolated and purified immediately by density gradient centrifugation at $2500 \mathrm{~g}$ for $30 \mathrm{~min}$. Then, the MSCs were resuspended in Dulbecco's modified Eagle's medium (Gibco, 11885-076) containing 10\% fetal bovine serum (Zhejiang Tianhang Biotechnology, 11011-8611) and seeded in culture flasks. After the cells were cultured in incubators at $37^{\circ} \mathrm{C}$ with $5 \% \mathrm{CO}_{2}$ for 2 days, the medium was replaced to remove the cells in suspension. Subsequently, the culture medium was replaced every 3 days. In addition, when the cells reached $80-90 \%$ confluence, they were digested by using $0.25 \%$ trypsin containing $0.53 \mathrm{mM}$ ethylenediamine tetraacetic acid (EDTA) and reseeded in two new culture flasks. In addition, the MSCs were used for the following experiments at passage 4 .

\section{Serum extraction and usage}

Peripheral blood from the HDs and AS patients was collected in EDTA anticoagulant tubes. Then, the blood was centrifuged at $2000 \mathrm{~g}$ for $15 \mathrm{~min}$, and heat-inactivation was performed by heating the samples at $56^{\circ} \mathrm{C}$ for $30 \mathrm{~min}$. Then, the serum was stored at $-80{ }^{\circ} \mathrm{C}$ until use, and $10 \%$ serum was used for MSCs culture.

\section{SA- $\beta$-Gal staining}

The Senescence-Associated $\beta$-gal Assay Kit was purchased from Beyotime Biotechnology (C0602), and SA$\beta$-gal staining was conducted according to the manufacturer's instructions. Briefly, MSCs were seeded in 6well plates and cultured with HD serum or AS serum for $72 \mathrm{~h}$. Then, the cells were washed with PBS and fixed with $1 \mathrm{ml}$ of fixing solution per well. After being incubated at room temperature for $15 \mathrm{~min}$, the cells were washed twice with PBS and incubated with a freshly prepared SA- $\beta$-gal staining solution in an incubator at $37^{\circ} \mathrm{C}$ with low $\mathrm{CO}_{2}$ for 16-18 h. Senescent cells were observed under a light microscope and evaluated by counting the number of blue-stained cells. For tissue slice staining, frozen sections were fixed with fixing solution for $15 \mathrm{~min}$ and stained with SA- $\beta$-gal staining solution in an incubator at $37^{\circ} \mathrm{C}$ with low $\mathrm{CO}_{2}$ for $16-18 \mathrm{~h}$. Then, the sections were counterstained with eosin and observed under a light microscope.

\section{Western blotting}

The relevant protocols were reported previously ${ }^{10}$. Briefly, MSCs were cultured with HD serum or AS serum for 2 days and lysed with RIPA buffer containing protease and phosphatase inhibitors for $30 \mathrm{~min}$ on ice. The lysates were collected and centrifuged at $14,000 \mathrm{rpm}$ for $30 \mathrm{~min}$ at $4{ }^{\circ} \mathrm{C}$. The protein concentrations of the lysates were detected with the BCA Protein Assay Kit (CWBIO, CW0014S), and equal amounts of proteins were mixed with a $5 \times$ sodium dodecyl sulfate (SDS) loading buffer. Then, the proteins were separated via SDSpolyacrylamide gel electrophoresis and transferred to 
polyvinylidene fluoride membranes (Millipore, IPVH0010). After being blocked with 5\% non-fat milk for $1 \mathrm{~h}$, the membranes were incubated with primary antibodies against p53 (1:1000, Cell Signaling Technology, 2524S), p21 (1:1000, Cell Signaling Technology, 2947S), p16 (1:1000, Cell Signaling Technology, 80772S) or GAPDH (1:2000, CWBIO, CW0100M) at $4{ }^{\circ} \mathrm{C}$ overnight. Then, the membranes were incubated with HRPconjugated secondary antibodies (1:3000, Boster, BA1050 and BA1054) for $1 \mathrm{~h}$ and detected by using Immobilon Western Chemiluminescent HRP Substrate (Millipore WBKLS0500).

\section{Frozen tissue section preparation}

Fresh articular soft tissue samples were collected from four AS patients and four non-AS patients (patients with osteonecrosis of the femoral head) during surgery. Then, the tissue samples were embedded in optimal cutting temperature $(\mathrm{OCT})$ compound and frozen with liquid nitrogen immediately. The frozen tissue samples were sectioned with a freezing microtome, and the sections were stored at $-80^{\circ} \mathrm{C}$ until use.

\section{Immunofluorescence}

MSCs seeded on coverslips or frozen sections of the above described tissue samples were fixed with paraformaldehyde for $15 \mathrm{~min}$ and subsequently permeabilized with $1 \%$ Triton X-100 for $20 \mathrm{~min}$. Then, the slides were blocked with $10 \%$ goat serum for $30 \mathrm{~min}$ and incubated with anti-p-H2A.X (1:400, Cell Signaling Technology, 9718T), anti-CD105 (1:500, Abcam, ab231774), anti-p53 (1:4,000, Cell Signaling Technology, 2524S), anti-p21 (1:250, Invitrogen, 33-7000), or anti-p16 (1: 1000, Abcam, ab16123) antibodies at $4{ }^{\circ} \mathrm{C}$ overnight. Then, the slides were stained with fluorophore-labeled secondary antibodies (1:500, Cell Signaling Technology, 4409S and 4412S), and 4',6-diamidino-2-phenylindole (DAPI) was used to stain cell nuclei. The slides were observed with a laser scanning confocal microscope (Nikon Eclipse Ni-E) or a fluorescence microscope according to the manufacturer's instructions.

\section{Cytokine array assay}

The Proteome Profiler Human XL Cytokine Array Kit (R\&D Systems, ARY022B) was used according to the manufacturer's instructions. The sera obtained from two AS patients and two HDs were used, and cytokine optical densities were quantified using HLImage++ software (Western Vision).

\section{Enzyme-linked immunosorbent assay (ELISA)}

The serum concentrations of CHI3L1 and PDGFA were detected using Quantikine ELISA kits for human CHI3L1 and PDGFA, respectively (R\&D Systems, DC3L10 and DY221), according to the manufacturer's instructions.
The absorbances of the reactants were measured using a Varioskan Flash Multimode Reader (Thermo Fisher), and the concentrations were determined according to the standard curves generated using the standard substance.

\section{AOPP detection}

The detection procedure was performed as described previously $^{24}$. The concentration of AOPPs in serum was assessed using spectrophotometry and is expressed in equivalents of chloramine-T. In brief, $40 \mu \mathrm{l}$ of serum diluted with $160 \mu \mathrm{l}$ of PBS, $200 \mu \mathrm{l}$ of chloramine-T (for calibration, Sigma, St. Louis, MO, USA) and $200 \mu \mathrm{l}$ of PBS (blank control) were added to a 96-well plate. Then, $20 \mu \mathrm{l}$ of acetic acid and $10 \mu \mathrm{l}$ of $1.16 \mathrm{M}$ potassium iodide were added to each well, and the absorbance at $340 \mathrm{~nm}$ was tested immediately. The concentrations of serum AOPPs are expressed as $\mu \mathrm{mol} / \mathrm{L}$ of chloramine- $\mathrm{T}$ equivalents.

\section{ROS detection}

Total ROS levels were measured with the Reactive Oxygen Species Assay Kit (Beyotime, China, S0033), which is based on the fluorescent probe DCFH-DA. Briefly, after being cultured with HD serum or AS serum for 2 days, MSCs were collected and incubated with $10 \mu \mathrm{mol}$ DCFH-DA for $20 \mathrm{~min}$ at $37^{\circ} \mathrm{C}$ while protected from light. Then, the cells were washed three times with serum-free medium, and the fluorescence of DCF (excitation: $488 \mathrm{~nm}$, emission: $530 \mathrm{~nm}$ ) was determined with a flow cytometer (BD Influx, BD Bioscience) and a fluorescence microscope. ROS levels are expressed as the mean fluorescence intensity (MFI) of DCF.

\section{Mitochondrial membrane potential detection}

Mitochondrial membrane potential $(\Delta \Psi \mathrm{m})$ was detected with the $\Delta \Psi \mathrm{m}$ Kit of JC-1 (Beyotime, China, C2006) according to the manufacturer's instruction. At a high $\Delta \Psi \mathrm{m}, \mathrm{JC}-1$ probes gather together and emit red fluorescence, while at a low $\Delta \Psi \mathrm{m}$, they remain monomers and emit green fluorescence. After being cultured with HD serum or AS serum for 2 days, MSCs were incubated and washed according to the kit protocol and then detected under a fluorescence microscope. The $\Delta \Psi \mathrm{m}$ is expressed as the fluorescence intensity ratio of red/green analyzed by ImageJ.

\section{ATP detection}

The ATP Assay Kit basing on firefly luciferase (Beyotime, China, S0026) was applied to determine cellular ATP levels according to the manufacturer's protocol. Briefly, MSCs were cultured with HD serum or AS serum for 2 days. Then, proteins were extracted, and the protein concentrations were measured according to the methods mentioned above. The ATP levels were detected with a luminometer and are expressed as $\mathrm{nmol} / \mathrm{mg}$ of protein. 


\section{Mitochondrial OCR detection}

The mitochondrial oxygen consumption rate (OCR) was determined by using the Seahorse XF Cell Mito Stress Test Kit (Seahorse, 103015-100) and Seahorse XF Cell Mito Stress Test Starter Pack (Seahorse, 102601-100) according to the manufacturer's instructions. Briefly, MSCs were cultured with HD serum or AS serum for 2 days and seeded in culture plates at a density of $2 \times 10^{4}$ MSCs per well. After being cultured at $37^{\circ} \mathrm{C}$ with $5 \% \mathrm{CO}_{2}$ overnight, the cells were washed twice with freshly prepared assay medium (10 $\mathrm{mM}$ glucose, $1 \mathrm{mM}$ pyruvate, and $2 \mathrm{mM}$ L-glutamine) and incubated in a low- $\mathrm{CO}_{2}$ incubator. Meanwhile, three compounds $(1 \mu \mathrm{M}$ oligomycin, $2 \mu \mathrm{M}$ FCCP, and $0.5 \mu \mathrm{M}$ antimycin A and rotenone) were added into specific reagent ports in the probe plates. Finally, calibration and measurement were executed with the Seahorse XFe96 Analyzer.

\section{Mitochondrial ROS detection}

Mitochondrial ROS levels were measured with MitoSOX $^{\mathrm{Tm}}$ Red Mitochondrial Superoxide Indicator (Invitrogen, M36008) according to the manufacturer's instructions. Briefly, MSCs were cultured with HD serum or AS serum for 2 days and then incubated with MitoSOX $(5 \mu \mathrm{M})$ diluted in Hanks' Balanced Salt Solution (HBSS; Invitrogen, 14025092) for $15 \mathrm{~min}$ at $37^{\circ} \mathrm{C}$. Then, the cells were washed three times and stained with DAPI. The fluorescence of MitoSOX (excitation: $510 \mathrm{~nm}$, emission: $580 \mathrm{~nm}$ ) was determined immediately with a fluorescence microscope.

\section{Statistical analysis}

All experiments were performed in triplicate, and MSC experiments were conducted with MSCs from three different donors. The investigator was blinded to the group allocation when assessing the outcome. All data were analyzed with SPSS 18.0 software and are presented as the mean \pm standard deviation (SD). Difference comparisons between two groups were performed using independentsample $t$ tests and nonparametric tests. Correlation analyses were executed via Pearson correlation and linear regression analysis. Homogeneity test of variances and normal distribution were determined before each test. $p<$ 0.05 was regarded as statistically significant.

\section{Results}

\section{AS serum induced MSC senescence}

To determine the effect of AS serum on MSCs senescence, we performed SA- $\beta$-gal staining and found that the frequency of SA- $\beta$-gal-positive cells increased remarkably when cells were treated with AS serum $(38.23 \pm 7.47 \%, p<0.001, n=20)$ compared with HD serum (15.66 $\pm 5.16 \%)$ (Fig. 1a, b). In addition, we examined the expression of the cell cycle arrest-related proteins $\mathrm{p} 53, \mathrm{p} 21$, and $\mathrm{p} 16$. The results showed that the expression of all three cell cycle arrest-related proteins in MSCs was higher after treatment with AS serum than after treatment with HD serum (Fig. 1c, d). We also evaluated the phosphorylation level of H2A.X (p-H2A.X), a marker of DNA damage that usually accompanies cellular senescence ${ }^{25}$, and discovered that

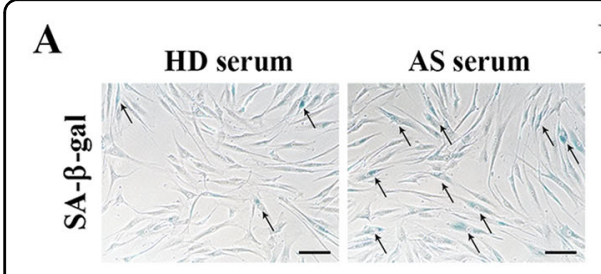

C

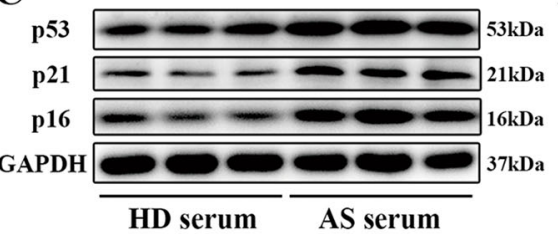

B

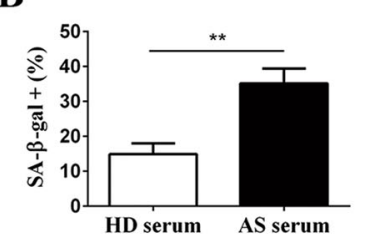

D

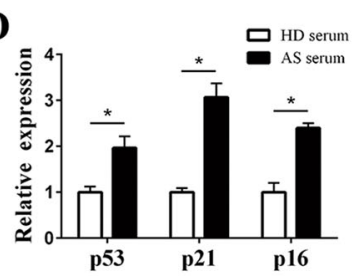

E
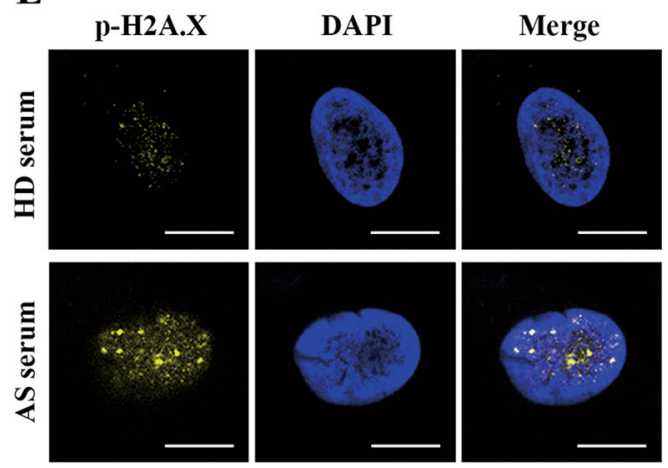

Fig. 1 Compared with HD serum, AS serum facilitated MSCs senescence. a MSCs treated with AS serum displayed stronger SA- $\beta$-gal staining

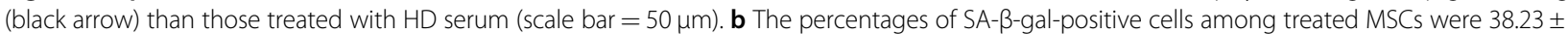
7.47\% and $15.66 \pm 5.16 \%$ for AS serum and HD serum, respectively; $n=20, p<0.001$. $\mathbf{c}$, $\mathbf{d}$ The expression of the cell cycle arrest-related proteins p53, p21, and p16 was detected by Western blotting, and the levels were higher in MSCs treated with AS serum than in those treated with HD serum. e The signal for $\mathrm{p}-\mathrm{H} 2 \mathrm{~A} . \mathrm{X}$ measured by immunofluorescence was more obvious in MSCs treated with AS serum than in those treated with HD serum (scale bar $=10 \mu \mathrm{m})$. The results are presented as the means \pm SD ( $n=20$, determined by independent-sample $t$ tests). All experiments were performed three independent times, ${ }^{*} p<0.05,{ }^{* *} p<0.01$. 
the fluorescence signal for $\mathrm{p}-\mathrm{H} 2 \mathrm{~A}$.X was more obvious in MSCs cultured with AS serum than in those cultured with HD serum (Fig. 1e). Furthermore, we analyzed the mRNA expression levels of SASP-related cytokines, including IL-6, IL-8, MCP1, MCP2, GRO, MIF, GM-CSF and three major immunoregulatory factors, IDO, LIF and TGF- $\beta$, in MSCs. The results showed that the levels of SASP-related cytokines were enhanced, while the expression levels of immunoregulatory factors were decreased in MSCs cultured with AS serum (Fig. S1A, B). Taken together, these findings demonstrated that in contrast to HD serum, AS serum dramatically facilitated the senescence of MSCs.

\section{MSCs located in the articular soft tissue of AS patients displayed distinct characteristics of senescence}

To determine whether MSC senescence exists in vivo in AS patients, we collected articular soft tissue samples from four AS patients and four non-AS patients and performed SA- $\beta$-gal staining and immunofluorescence on frozen sections of these tissue samples. As shown in Fig. $2 \mathrm{a}$, tissues from AS patients displayed stronger SA- $\beta$-gal staining than those from non-AS donors. In addition, in Fig. 2b-d, tissue-located MSCs in AS patients, which were labeled with CD105, expressed the cell cycle arrest-related proteins $\mathrm{p} 53, \mathrm{p} 21$, and $\mathrm{p} 16$ in greater abundance than tissue-located MSCs in non-AS patients, which indicated that MSC senescence was present to a larger extent in the AS patients.

\section{AOPPs were enhanced in AS serum and positively correlated with the senescence-promoting effect of AS serum}

To explore the factors in AS serum responsible for MSC senescence, we first performed a cytokine array on HD and AS sera and found that CHI3L1 and PDGFA expression levels were increased in AS serum, which were further verified by ELISA (Fig. S2A). We further measured the effects of CHI3L1 and PDGFA on MSC senescence but found that neither CHI3L1 nor PDGFA influenced the SA- $\beta$-gal staining or the expression levels of p53, p21, and p16 in MSCs (Fig. S2B, C).

Oxidative stress is a major inducer of senescence in organisms $^{26}$, and AOPPs are capable of inducing ROS production and subsequent cell cycle arrest ${ }^{24}$. Therefore, we suspected that AOPPs had a role in the senescencepromoting effect of AS serum. We detected the level of AOPPs and found that AOPPs expression was markedly elevated in AS serum $(108.0 \pm 11.69 \mu \mathrm{mol} / \mathrm{L})$ compared with HD serum $(44.63 \pm 9.41 \mu \mathrm{mol} / \mathrm{L}, p<0.001, n=20)$ (Fig. 3a). Furthermore, we performed correlation analyses of the AOPPs level with the CRP level and disease activity. As expected, the level of AOPPs in AS serum was strongly and positively correlated with the CRP level and BASDAI scores (Fig. 3b, c). More critically, we determined that the AOPPs level possessed significant positive relations with the percentage of SA- $\beta$-gal-positive cells (Fig. $3 \mathrm{~d}$ ) and the expression of p53 (Fig. 3e), p21 and p16 (data not shown). In sum, these results suggested that the enhanced level of AOPPs was responsible for the senescence-promoting effect of AS serum.

\section{AS serum caused ROS excess in MSCs}

Many studies have reported that ROS can be induced by AOPPs and play a vital role in triggering cellular senescence $^{24,27}$. We wondered whether exposure to AS serum would increase ROS production in MSCs. Thus, we detected the ROS level with the probe DCFH-DA and discovered that the ROS levels of MSCs were quite higher in the AS serum group than in the HD serum group, as displayed by a stronger MFI for DCF measured by flow cytometry (Fig. 3f, g) together with brighter fluorescence found by fluorescence microscopy (Fig. 3h).

\section{$\mathrm{N}$-acetylcysteine inhibited ROS production and rescued MSCs from senescence}

To validate the role of ROS in the senescencepromoting effect of AS serum, we suppressed the production of ROS with N-acetylcysteine (NAC), a widely used inhibitor of $\mathrm{ROS}^{28}$. As the level of ROS was reduced by NAC treatment (Fig. 4a, b), the increased percentage of SA- $\beta$-gal-positive cells (Fig. 4c, d) together with the expression of p53, p21, and p16 (Fig. 4e, f) in MSCs caused by AS serum returned to normal levels. These findings revealed that AS serum stimulated ROS production in MSCs and that NAC was able to reduce the ROS level and rescue MSC senescence induction by AS serum.

\section{Mitochondrial dysfunction of MSCs was mediated by AS serum}

The mitochondria are the major origin of cellular $\operatorname{ROS}^{29}$. To determine the mechanism responsible for the ROS excess, we determined the mitochondrial function of MSCs treated with AS serum or HD serum. First, we conducted $\Delta \Psi \mathrm{m}$ detection basing on $\mathrm{JC}-1$ and found that compared to HD serum, AS serum obviously decreased the $\Delta \Psi \mathrm{m}$ of MSCs (Fig. 5a, b). In addition, the ATP production of MSCs was also reduced after AS serum treatment (Fig. 5c). Then, we determined the OCR and found that both the basal respiration and the spare respiration of MSCs were impaired by AS serum (Fig. $5 \mathrm{~d}$, e). In addition, reduced ATP production was also found in the OCR assay (Fig. 5d, e). Furthermore, we treated the MSCs with ROS scavenger NAC and measured the OCR and ATP production. The results showed that NAC treatment improved the OCR and ATP production in MSCs cultured with AS serum but not HD serum 

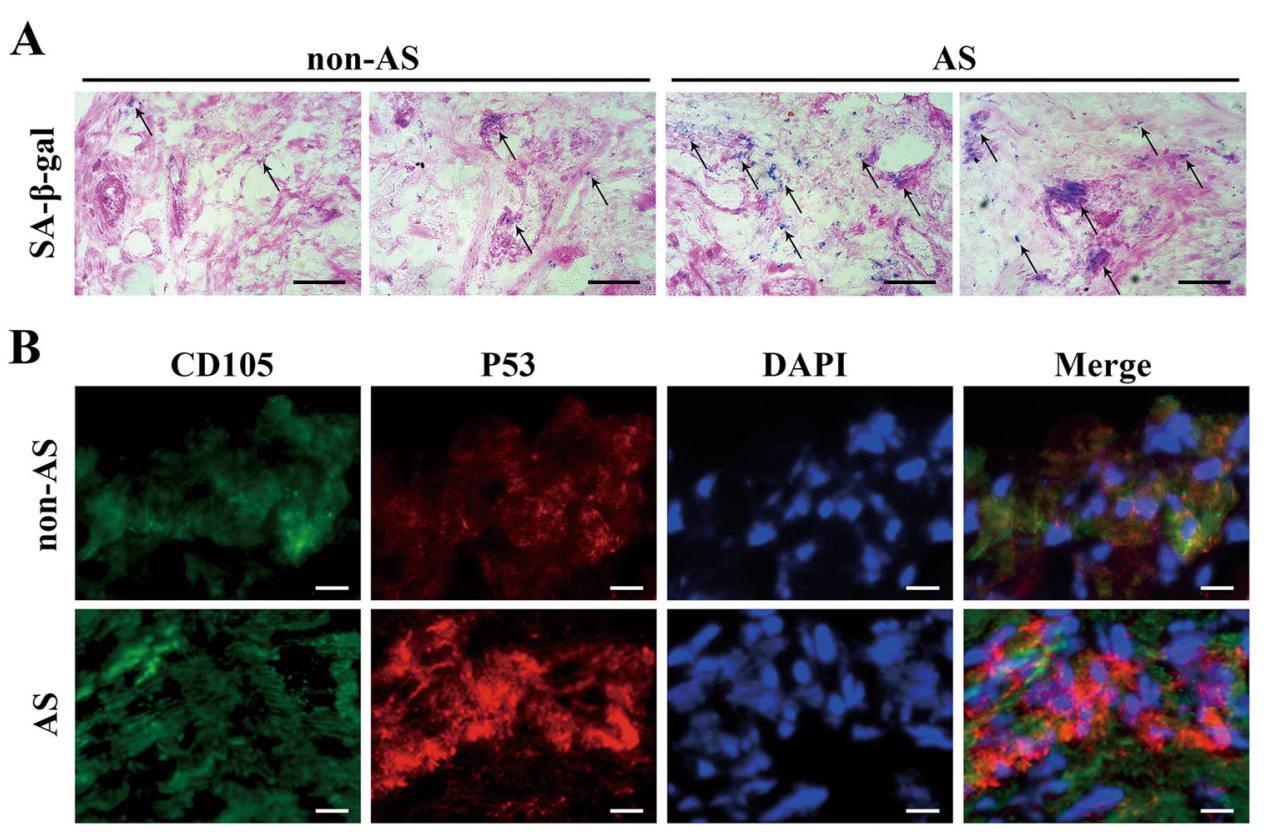

C

\section{CD105}
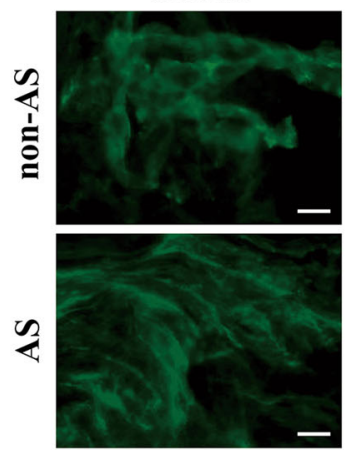

D

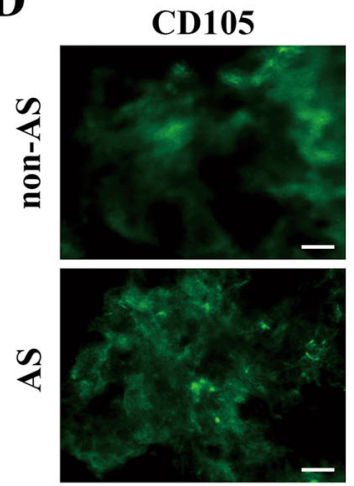

P21
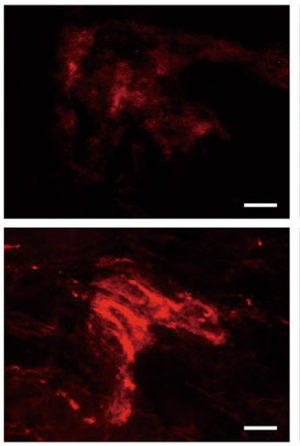

P16
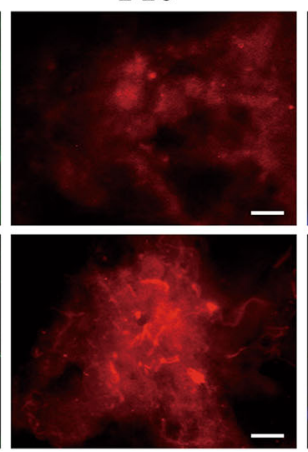

DAPI
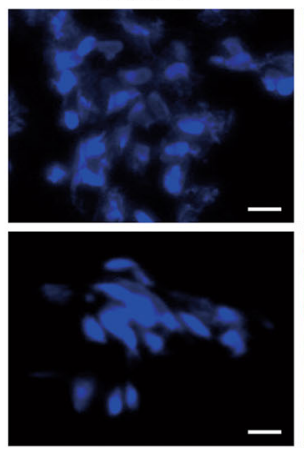

DAPI
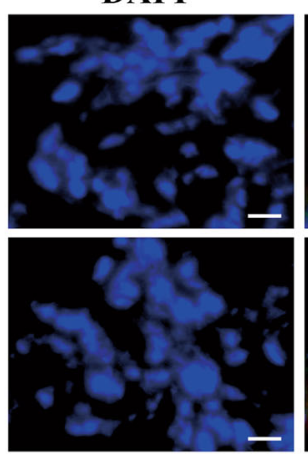

Merge
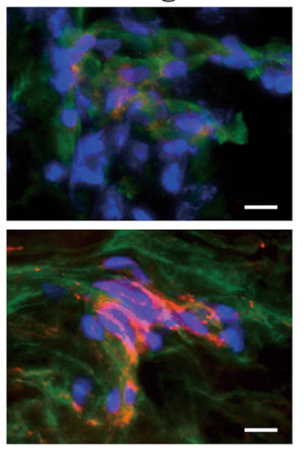

Merge

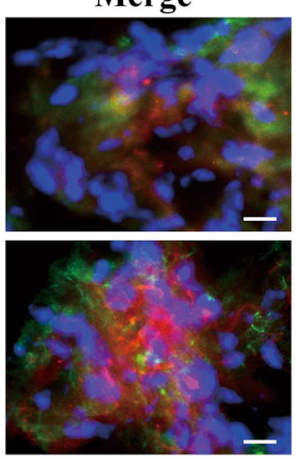

Fig. 2 MSCs located in the articular soft tissue of AS patients displayed remarkable characteristics of senescence. a Tissues from AS patients displayed stronger SA- $\beta$-gal staining (black arrow) than those from non-AS donors (scale bar $=100 \mu \mathrm{m}$ ). b-d Immunofluorescence detection indicated increased levels of p53 (b), p21 (c), and p16 (d) in MSCs in articular soft tissue samples from AS patients than in those from non-AS patients (scale bar $=40 \mu \mathrm{m})$. All experiments were performed three independent times $(n=4)$.

(Fig. S3A-C). In addition, with NAC treatment, there were not statistically significant differences in OCR and ATP production between MSCs treated with AS serum and MSCs treated with HD serum (Fig. S3A-C). In summary, all these results illustrated that AS serum treatment resulted in MSCs mitochondrial dysfunction. 

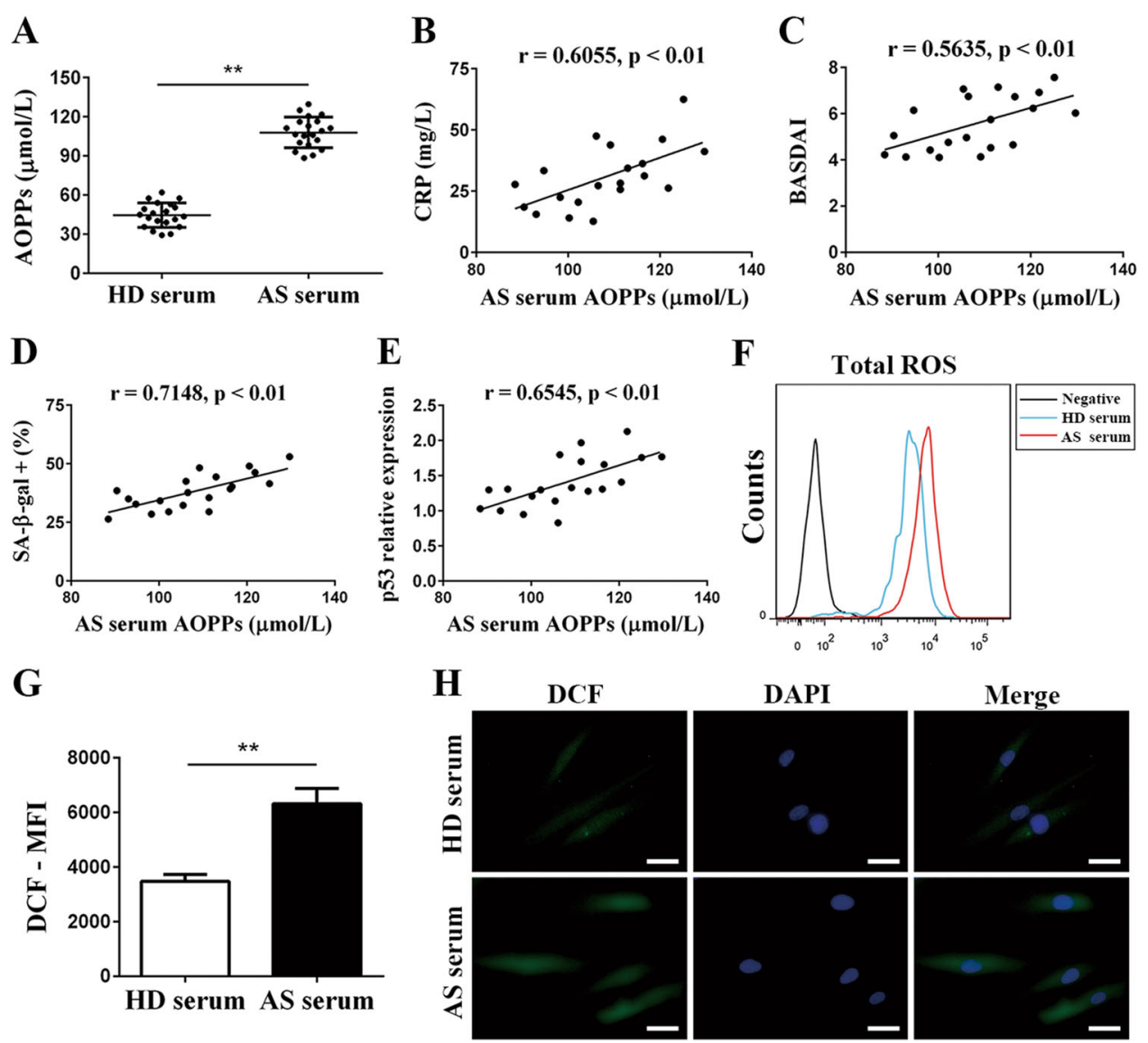

Fig. 3 AS serum contained elevated AOPPs levels and could stimulate ROS production in MSCs. a The levels of AOPPs were higher in AS serum $(108.0 \pm 11.69 \mu \mathrm{mol} / \mathrm{L})$ than in HD serum $(44.63 \pm 9.41 \mu \mathrm{mol} / \mathrm{L}) ; p<0.001, n=20$. b-e The levels of AOPPs in AS serum were positively correlated with the level of CRP $(r=0.6055, p<0.01)(\mathbf{b})$, BASDAI scores $(r=0.5635, p<0.01)(\mathbf{c})$, the percentage of SA- $\beta$-gal-positive cells after treatment with AS serum $(r=0.7148, p<0.01)(\mathbf{d})$, and the expression of the protein p53 in MSCs treated with AS serum $(r=0.65458, p<0.01)(\mathbf{e}-\mathbf{g})$. Flow cytometry detection revealed that the total ROS level was enhanced in MSCs treated with AS serum compared with those treated with HD serum. $\mathbf{h}$ AS serum-treated MSCs displayed a stronger signal for ROS than HD serum-treated MSCs under a fluorescence microscope (scale bar = $20 \mu \mathrm{m})$. The results in $\mathbf{a}, \mathbf{f}$, and $\mathbf{g}$ are presented as the means \pm SD $(n=20$, determined by independent-sample $t$ tests). The data in $\mathbf{b}$-e were determined by Pearson correlation and linear regression analysis $(n=20)$. All experiments were performed three independent times, ${ }^{*} p<0.05$, ${ }^{* *} p<0.01$

\section{MQ reversed the excess mitochondrial ROS production and} MSCs senescence induced by AS serum

To determine whether mitochondrial dysfunction was the source of the excess ROS, we detected mitochondrial ROS by using the probe MitoSOX, and the results showed that in comparison with HD serum, AS serum enhanced the mitochondrial ROS level of MSCs (Fig. 6a). In addition, by adding mitoquinone (MQ), a mitochondriontargeted antioxidant ${ }^{30}$, the mitochondrial ROS level (Fig. 6a) together with the total ROS level (Fig. 6b, c) of MSCs treated with AS serum returned to the levels seen in HD serum-treated MSCs. Furthermore, MQ pretreatment successfully alleviated the influence of AS serum on MSCs senescence, which was indicated by the reduced percentage of SA- $\beta$-gal-positive cells (Fig. $6 \mathrm{~d}$, e) and expression of p53, p21, and p16 (Fig. 6f, g). Taken together, these data confirmed that AS serum increased mitochondrial ROS levels in MSCs and that targeting mitochondrial ROS was able to relieve the senescence-promoting effect of AS serum.

\section{Discussion}

In this study, we focused on the influence of the AS serum environment on MSCs and discovered that compared to HD serum, AS serum strikingly facilitated MSCs senescence. Further mechanistic studies revealed that AOPPs in AS serum mediated mitochondrial dysfunction, inducing excess ROS production that resulted in MSC senescence.

The microenvironment is of great importance in organisms, and the serum environment is a vital part of $\mathrm{it}^{31,32}$. Many studies have reported that an abnormal 

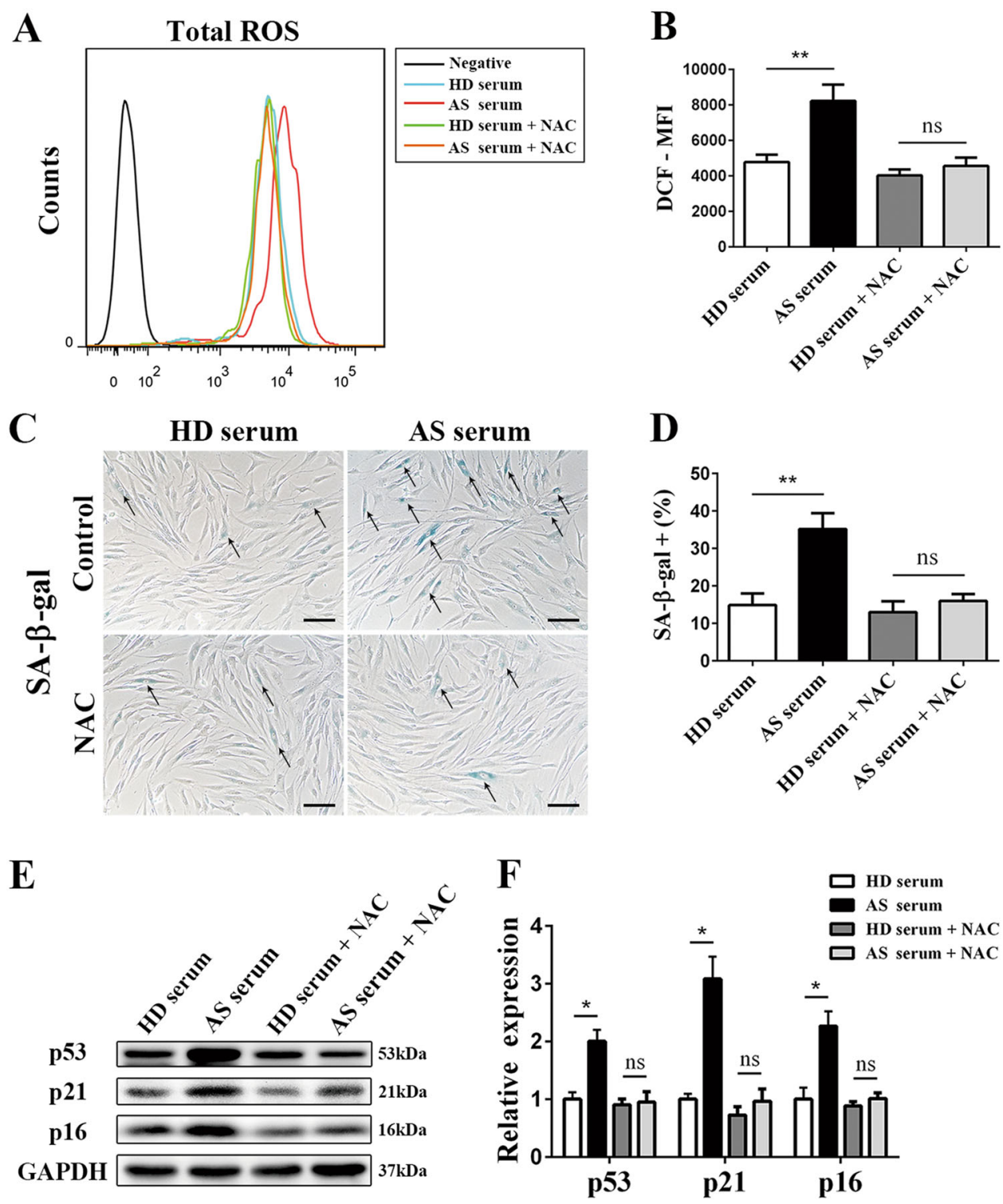

Fig. 4 ROS inhibition via NAC rescued MSCs from the senescence caused by AS serum. $\mathbf{a}, \mathbf{b}$ NAC reduced the ROS level in AS serum-treated MSCs to the level in HD serum-treated MSCs. c, $\mathbf{d}$ NAC rescued the extent of SA- $\beta$-gal staining of MSCs (black arrow) induced by AS serum (scale bar $=50 \mu \mathrm{m})$. e, $\mathbf{f}$ NAC decreased the expression levels of the cell cycle arrest-related proteins p53, p21, and p16 in AS serum-treated MSCs to the levels in HD serum-treated MSCs. The results are presented as the means \pm SD $(n=10$, determined by independent-sample $t$ tests). All experiments were performed three independent times, ${ }^{*} p<0.05,{ }^{* *} p<0.01$.

serum environment affects cell functions and participates in disease development ${ }^{19,33}$. For AS, studies have found that the levels of various inflammatory factors such as TNF- $\alpha$ and IL17 and oxidative stress are abnormally increased in AS serum ${ }^{3,34}$. However, the specific influence of AS serum on cells in organism has rarely been reported. MSCs possess a strong immunomodulatory ability and the capacity for trilineage differentiation ${ }^{6}$. MSC dysfunction participates in several inflammatory and articular diseases $^{7}$. Previously, we found that MSCs from AS patients displayed multiple functional abnormalities ${ }^{9-11}$; however, the underlying reason was uncertain but might be related to the AS serum environment. Therefore, in this study, we explored the impact of AS serum on MSCs and confirmed that in contrast to HD serum, AS serum dramatically facilitated MSCs senescence. In addition, we discovered enhanced expression of the cell cycle arrestrelated proteins p53 and p21 in MSCs from AS articular tissue samples by immunofluorescence, which was in agreement with our in vitro findings. Similar to what we found in AS serum, serum from SLE and SSc patients also accelerates the senescence of MSCs, thereby influencing 


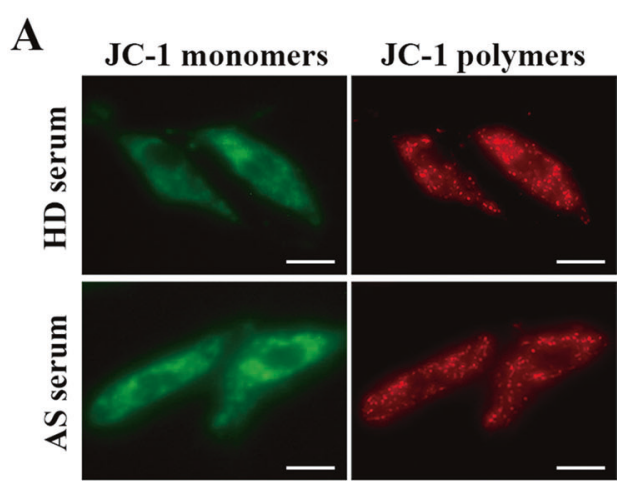

B

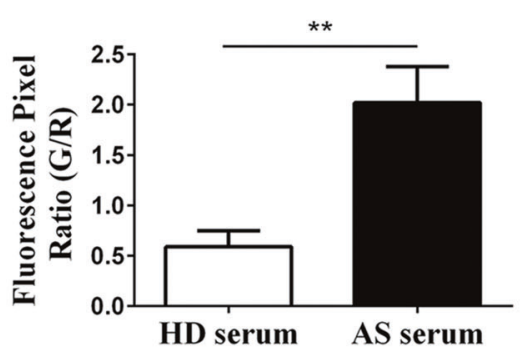

D

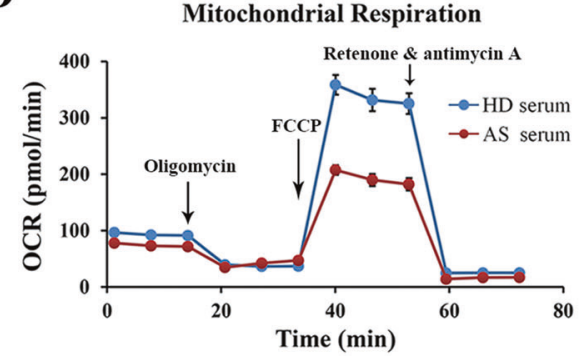

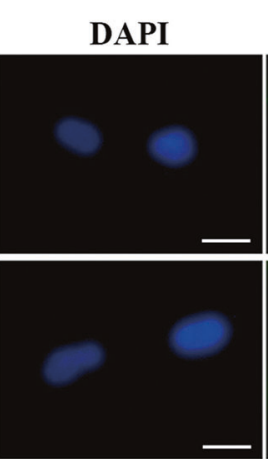

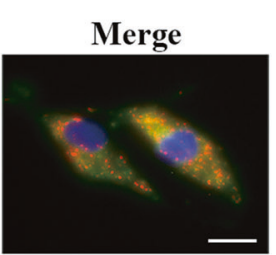

C
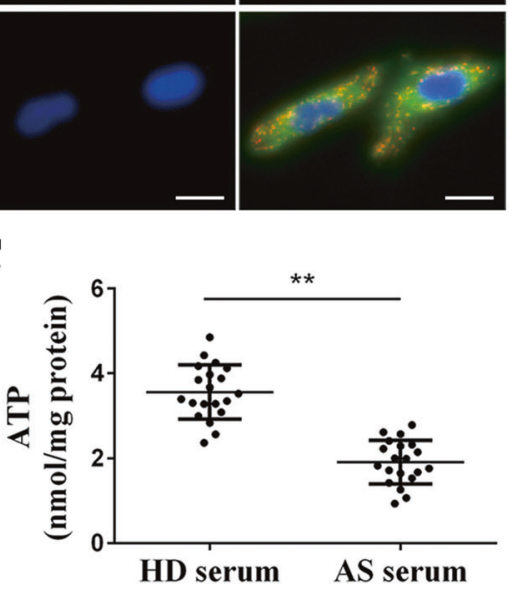

$\mathbf{E}$

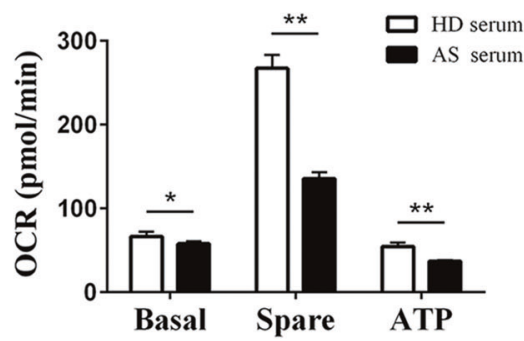

Fig. 5 AS serum-mediated mitochondrial dysfunction in MSCs. a The mitochondrial membrane potential detected by the probe JC-1 showed reduced fluorescence of JC-1 polymers and elevated fluorescence of JC-1 monomers in MSCs treated with AS serum, which represented a reduced $\Delta \Psi \mathrm{m}$ in the AS serum-treated MSCs (scale bar $=10 \mu \mathrm{m}$ ). $\mathbf{b}$ The fluorescence index analyzed by ImageJ showed that the ratio of JC-1 monomers (green) to polymers (red) was higher in MSCs treated with AS serum than in those treated with HD serum, which implied a reduced $\triangle \Psi_{\mathrm{m}}$ in the AS serum-treated MSCs. c ATP detection showed that AS serum treatment obviously reduced the ATP production of MSCs. d, e Mitochondrial oxygen consumption rate detection revealed that compared to HD serum, AS serum impaired the basal respiration, spare respiration and ATP production of MSCs. The results are presented as the means \pm SD $(n=10$, determined by independent-sample $t$ tests). All experiments were performed three independent times, ${ }^{*} p<0.05,{ }^{* *} p<0.01$.

disease development ${ }^{19,20}$. These findings together implied pathogenic roles for the morbid serum environment and MSCs senescence in autoimmune diseases. Accordingly, we proposed that the chronically morbid serum microenvironment of AS participates in disease development through facilitating MSCs senescence.

Though serum from several different autoimmune disease patients have similar impacts on MSCs senescence, the intrinsic mechanisms are different. In SLE, increased leptin and NAP2 levels are responsible for the senescence-promoting effect on MSCs ${ }^{19}$. In SSc, serumderived oxidative stress facilitates MSCs senescence ${ }^{20}$. Previously, we discovered an imbalance between oxidant biomarker and antioxidant levels in AS serum, which implied that disordered redox may participate in $\mathrm{AS}^{5}$. In this study, we found that AOPPs levels in AS serum were strongly and positively correlated with the extent of SA$\beta$-gal staining and the expression of cell cycle arrestrelated proteins in MSCs cultured with AS serum. In AS patients, serum AOPPs levels have been reported to be elevated and positively corelated with the CRP level, the erythrocyte sedimentation rate and disease activity indexes, such as the BASDAI ${ }^{35}$, which agreed with the results of our study. Then, whether AOPPs are simply an accompanying marker or are actually engaged in AS pathogenesis remains to be determined. Previously, studies illustrated that AOPPs were closely related to inflammation and immune dysregulation ${ }^{36}$. In addition, 


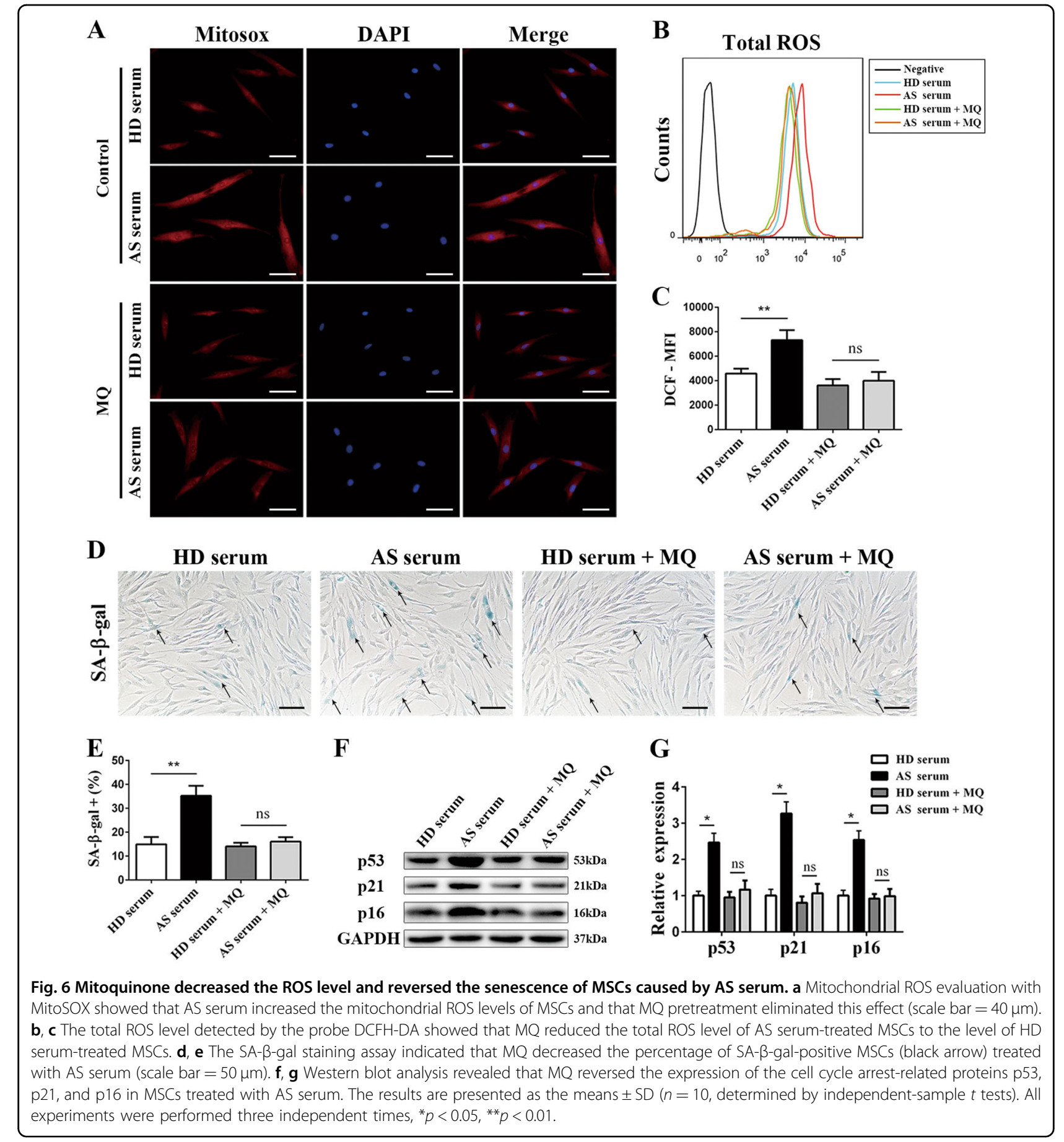

B

recent studies have reported that AOPPs are not only an oxidant marker but also capable of inducing oxidative stress and cell cycle arrest ${ }^{24}$. In view of these reports and our findings reported in this study, we speculate that AOPPs are not only an accompanying marker but also participants in AS pathogenesis through the induction of MSCs senescence and may be a potential therapeutic target for AS treatment.
Excess ROS is a common cause of cellular senescence and has been implicated in several inflammatory diseases $^{27,37}$. In AS, studies have reported that ROS levels are enhanced in leukocytes and ROS are considered to be a potential mediator of AS pathogenesis ${ }^{38,39}$. We discovered that AS serum stimulated ROS production in MSCs and targeting ROS was able to rescue MSCs from senescence. Previous studies discovered that senescent MSCs 
exhibited impaired immunoregulatory function and elevated pro-inflammatory factor expression, which might cause an inflammatory reaction ${ }^{19}$. In addition, an inflammatory stimulus was able to initiate a respiratory burst and result in oxidative stress production ${ }^{40}$. Furthermore, it has been reported that oxidative stress can serve as a primary disorder and induce a secondary disorder, which further increases oxidative stress ${ }^{41}$. All these findings imply that such a vicious cycle might occurs in AS: the oxidative stress in AS serum induce excessive ROS production and MSCs senescence, and then the senescent MSCs lead to an inflammatory reaction, with the consequent inflammation further increasing oxidative stress. Therefore, we propose that ROS may be of great importance in AS development, especially in chronic inflammation, and that ROS are a potential target for AS therapy. Consistent with our assumption, previous studies have reported that several kinds of drugs for AS, including nonsteroidal anti-inflammatory drugs (NSAIDs) and sulfasalazine, are capable of inhibiting $\operatorname{ROS}^{42,43}$, which may contribute to their anti-inflammatory effects. Further clinical studies targeting ROS are required to validate these hypotheses.

Mitochondria are the major origin of ROS, and mitochondrial dysfunction participates in ageing and several autoimmune diseases, such as RA and inflammatory bowel disease ${ }^{44,45}$. However, few studies have explored the role of mitochondria in AS. There are only analytical studies that have predicted that the pathway of mitochondrial dysfunction and some mitochondrion-related proteins may be involved with $\mathrm{AS}^{46,47}$. In this study, we explored mitochondrial function in AS and discovered that the AS serum environment induced mitochondrial dysfunction in MSCs and subsequently raised ROS levels and caused MSCs senescence. Thus, we propose that mitochondrial dysfunction participates in AS pathogenesis and may be a new therapeutic target in AS. Recent studies have reported that the JAK/STAT blockers tofacitinib and filgotinib, which are capable of improving mitochondrial function, are efficacious in the treatment of $\mathrm{AS}^{48,49}$, supporting a role for the mitochondria in AS.

Then, what is the specific mechanism underlying the mitochondrial dysfunction caused by AS serum? The electron transfer chain (ETC), which mainly consists of four components named complexes I to IV, is the core part of the mitochondria ${ }^{50}$. It can be disrupted by oxidative stress, resulting in a reduced oxidative phosphorylation rate and decreased ATP production, followed by ROS overproduction ${ }^{51}$. Our results showed that basal respiration and spare respiration together with ATP production were impaired in the AS serum environment, indicating impairment of the ETC. A genes analysis study of AS revealed that the most significant gene ontology (GO) enrichment was in the category of respiratory electron transport chain, which also suggested the presence of ETC impairment in $\mathrm{AS}^{46}$. Furthermore, this study also reported that several complex I- and IV-related genes exhibited downregulated expression in AS, implying the mechanism of ETC impairment in AS. Further studies are supposed to explore the specific mechanism underlying ETC impairment and therapies targeting mitochondrial dysfunction in AS.

MSC dysfunction is closely related to inflammation in organisms and is implicated in autoimmune diseases, including RA, SLE, and $\mathrm{AS}^{52}$. Recently, studies have found that cellular senescence influences both the immunoregulation and differentiation abilities of MSCs and, therefore, mediates disease development ${ }^{18,19,53}$. We found that the AS serum environment induced MSC senescence, but how senescent MSCs participate in AS is still being evaluated. Chronic inflammation is the core part of AS pathogenesis, and the dysregulation of macrophages and $\mathrm{T}$ cells plays a crucial role in this process ${ }^{2}$. In AS, T cells and macrophages are the most frequent cells located in early and active sacroiliitis ${ }^{54}$. In addition, the pro-inflammatory M1 macrophages, Th1 cells and Th17 cells are expanded in AS and lead to the abnormally elevated levels of TNF- $\alpha$ and IL-17, two factors mainly responsible for the chronic inflammation and joint damage in $\mathrm{AS}^{55}$. Under normal conditions, MSCs possess strong immunomodulatory capability on macrophages and $\mathrm{T}$ cells. MSCs are capable of shifting proinflammatory M1 macrophages into anti-inflammatory M2 macrophages by secreting immunoregulatory factors $^{56}$. In addition, MSCs are able to modulate the Th1/ Th2 and Th17/Treg balance, thereby reducing the production levels of pro-inflammatory cytokines such as TNF- $\alpha$ and IL-1 $7^{57,58}$. However, when entering senescence, MSCs immunomodulatory ability becomes impaired, and a pro-inflammatory SASP occurs ${ }^{19}$. In this study, we found that AS serum-induced senescent MSCs expressed reduced levels of immunomodulatory factors, including LIF, IDO and TGF- $\beta$, indicating that the suppressive effects of MSCs on T cells and macrophages become impaired and that serious pro-inflammatory phenotypes of $\mathrm{T}$ cells and macrophages may occur in AS. In addition, we also revealed that senescent MSCs induced by AS serum possessed an SASP with higher expression of several pro-inflammatory cytokines, such as IL-6, MIF, MCP1, and GM-CSF. These cytokines are closely related to AS pathogenesis. IL-6 and MIF are increased in AS and capable of activating $\mathrm{T}$ cells and macrophages to express TNF- $\alpha$ or IL- $17^{59,60}$. MCP1 and GM-CSF play important roles in the pro-inflammatory function and migration of macrophages ${ }^{61,62}$. Taken together, we deem that senescence establishment in MSCs could lead to pro-inflammatory phenotypes of $\mathrm{T}$ cells, macrophages and excessive production of TNF- $\alpha$ 
and IL-17, thereby triggering or aggravating the inflammation in AS.

In past decades, MSCs have been widely used to treat inflammatory diseases ${ }^{63}$. While many clinical studies have reported that the efficacy of MSCs infusion are supposed to be improved. For instance, Sun reported that MSCs transplantation was a hopeful treatment for SLE but only $32.5 \%$ of patients achieved a major clinical response ${ }^{64}$. Previously, we determined that intravenous infusion of MSCs from HDs was effective for AS treatment, but a considerable proportion of the patients did not respond ${ }^{12}$. We speculated that this treatment failure might be related to the impact of the patients' internal microenvironment on the functions of MSCs. In this study, we discovered that the AS serum environment strikingly facilitated the senescence of MSCs. Likewise, the infused MSCs would be affected similarly, thereby losing their immunomodulatory function and therapeutic effect. These findings implied that targeting oxidative stress in the serum might be a feasible way to improve the outcome of MSCs therapy in AS.

In conclusion, we demonstrated that the AS serum environment mediated mitochondrial dysfunction and facilitated MSCs senescence. These findings may help elucidate the pathogenesis of AS and provide new targets for AS treatment. However, there are some limitations to this study. What is the specific mechanism of mitochondrial dysfunction? What are the efficacies of therapies aimed at the abovementioned targets? Further mechanistic and clinical studies are required to solve these problems.

\section{Acknowledgements}

The authors thank American Journal Experts for providing English language editing of the manuscript. This study was financially supported by the National Natural Science Foundation of China (81700884 and 81971518) and the Key Realm R\&D Program of Guangdong Province (2019B020236001) and the Fundamental Research Funds for the Central Universities (19ykpy01).

\section{Author details \\ 'Department of Orthopedics, Sun Yat-Sen Memorial Hospital, Sun Yat-Sen University, Guangzhou 510120, P.R. China. ${ }^{2}$ Department of Orthopedics, The Eighth Affiliated Hospital, Sun Yat-Sen University, Shenzhen 518033, P.R. China. ${ }^{3}$ Shenzhen Futian Hospital for Rheumatic Diseases, Shenzhen 518040, P.R. China. ${ }^{4}$ Center for Biotherapy, The Eighth Affiliated Hospital, Sun Yat-Sen University, Shenzhen 518033, P.R. China. ${ }^{5}$ Center for Biotherapy, Sun Yat-Sen Memorial Hospital, Sun Yat-Sen University, Guangzhou 510120, P.R. China}

\section{Conflict of interest}

The authors declare that they have no conflict of interest.

\section{Publisher's note}

Springer Nature remains neutral with regard to jurisdictional claims in published maps and institutional affiliations.

Supplementary Information accompanies this paper at (https://doi.org/ 10.1038/s41419-020-02993-x)
Received: 1 April 2020 Revised: 3 September 2020 Accepted: 7 September 2020

Published online: 17 September 2020

\section{References}

1. Braun, J. \& Sieper, J. Ankylosing spondylitis. Lancet 369, 1379-1390 (2007).

2. Sieper, J. \& Poddubnyy, D. Axial spondyloarthritis. Lancet 390, 73-84 (2017).

3. Gratacos, J. et al. Serum cytokines (IL-6, TNF-alpha, IL-1 beta and IFN-gamma) in ankylosing spondylitis: a close correlation between serum IL-6 and disease activity and severity. Br. J. Rheumatol. 33, 927-931 (1994).

4. Karakoc, M., Altindag, O., Keles, H., Soran, N. \& Selek, S. Serum oxidativeantioxidative status in patients with ankylosing spondilitis. Rheumatol. Int. 27, 1131-1134 (2007).

5. Wang, L. et al. The relationship of bone mineral density to oxidant/antioxidant status and inflammatory and bone turnover markers in a multicenter crosssectional study of young men with ankylosing spondylitis. Calcif. Tissue Int. 97, 12-22 (2015)

6. Ding, D. C., Shyu, W. C. \& Lin, S. Z. Mesenchymal stem cells. Cell Transplant. 20 5-14 (2011).

7. Berthelot, J.-M., Le Goff, B. \& Maugars, Y. Bone marrow mesenchymal stem cells in rheumatoid arthritis, spondyloarthritis, and ankylosing spondylitis: problems rather than solutions? Arthritis Res. Ther. 21, 239 (2019).

8. Campbell, T. M. et al. Mesenchymal stem cell alterations in bone marrow lesions in patients with hip osteoarthritis. Arthritis Rheumatol. 68, 1648-1659 (2016).

9. $\mathrm{Wu}, \mathrm{Y}$. et al. Reduced immunomodulation potential of bone marrow-derived mesenchymal stem cells induced CCR4+CCR6+ Th/Treg cell subset imbalance in ankylosing spondylitis. Arthritis Res. Ther. 13, R29 (2011).

10. Xie, Z. et al. Imbalance between bone morphogenetic protein 2 and noggin induces abnormal osteogenic differentiation of mesenchymal stem cells in ankylosing spondylitis. Arthritis Rheumatol. 68, 430-440 (2016).

11. Liu, W. et al. Abnormal inhibition of osteoclastogenesis by mesenchymal stem cells through the miR-4284/CXCL5 axis in ankylosing spondylitis. Cell Death Dis. 10, 188 (2019).

12. Wang, P. et al. Effects and safety of allogenic mesenchymal stem cell intravenous infusion in active ankylosing spondylitis patients who failed NSAIDs: a 20-week clinical trial. Cell Transplant. 23, 1293-1303 (2014).

13. Kuilman, T., Michaloglou, C., Mooi, W. J. \& Peeper, D. S. The essence of senescence. Genes Dev. 24, 2463-2479 (2010).

14. Munoz-Espin, D. \& Serrano, M. Cellular senescence: from physiology to pathology. Nat. Rev. Mol. Cell Biol. 15, 482-496 (2014).

15. Salama, R., Sadaie, M., Hoare, M. \& Narita, M. Cellular senescence and its effector programs. Genes Dev. 28, 99-114 (2014)

16. He, S. \& Sharpless, N. E. Senescence in health and disease. Cell 169, 1000-1011 (2017).

17. Wagner, W. et al. Replicative senescence of mesenchymal stem cells: a continuous and organized process. PLOS ONE 3, e2213 (2008).

18. Turinetto, V., Vitale, E. \& Giachino, C. Senescence in human mesenchymal stem cells: functional changes and implications in stem cell-based therapy. Int. J. Mol. Sci. 17, E1164 (2016).

19. Gao, L. et al. Bone marrow-derived mesenchymal stem cells from patients with systemic lupus erythematosus have a senescence-associated secretory phenotype mediated by a mitochondrial antiviral signaling protein-interferonB feedback loop. Arthritis Rheumatol. 69, 1623-1635 (2017).

20. Fonteneau, G. et al. Serum-mediated oxidative stress from systemic sclerosis patients affects mesenchymal stem cell function. Front. Immunol. 8, 988 (2017).

21. van der Linden, S., Valkenburg, H. A. \& Cats, A. Evaluation of diagnostic criteria for ankylosing spondylitis. A proposal for modification of the New York criteria. Arthritis Rheum. 27, 361-368 (1984).

22. Zochling, J. Measures of symptoms and disease status in ankylosing spondylitis: Ankylosing Spondylitis Disease Activity Score (ASDAS), Ankylosing Spondylitis Quality of Life Scale (ASQoL), Bath Ankylosing Spondylitis Disease Activity Index (BASDAI), Bath Ankylosing Spondylitis Functional Index (BASFI), Bath Ankylosing Spondylitis Global Score (BAS-G), Bath Ankylosing Spondylitis Metrology Index (BASMI), Dougados Functional Index (DFI), and Health Assessment Questionnaire for the Spondylarthropathies (HAQ-S). Arthritis Care Res. 63, S47-S58 (2011).

23. Colter, D. C., Class, R., DiGirolamo, C. M. \& Prockop, D. J. Rapid expansion of recycling stem cells in cultures of plastic-adherent cells from human bone marrow. Proc. Natl Acad. Sci. USA 97, 3213-3218 (2000). 
24. Sun, S. et al. Advanced oxidation protein products induce S-phase arrest of hepatocytes via the ROS-dependent, $\beta$-catenin-CDK2-mediated pathway. Redox Biol. 14, 338-353 (2018).

25. d'Adda di Fagagna, F. et al. A DNA damage checkpoint response in telomereinitiated senescence. Nature 426, 194-198 (2003).

26. Chen, F., Liu, Y., Wong, N. K., Xiao, J. \& So, K. F. Oxidative stress in stem cell aging. Cell Transplant. 26, 1483-1495 (2017).

27. Colavitti, R. \& Finkel, T. Reactive oxygen species as mediators of cellular senescence. IUBMB Life 57, 277-281 (2005).

28. Zafarullah, M., Li, W. Q., Sylvester, J. \& Ahmad, M. Molecular mechanisms of Nacetylcysteine actions. Cell. Mol. Life Sci. 60, 6-20 (2003).

29. Slimen, I. B. et al. Reactive oxygen species, heat stress and oxidative-induced mitochondrial damage. A review. Int. J. Hyperthermia 30, 513-523 (2014).

30. Murphy, M. P. \& Smith, R. A. Targeting antioxidants to mitochondria by conjugation to lipophilic cations. Annu. Rev. Pharmacol. Toxicol. 47, 629-656 (2007).

31. Wang, M. et al. Role of tumor microenvironment in tumorigenesis. J. Cancer $\mathbf{8}$, 761-773 (2017).

32. Ecke, A. et al. Tissue specific differentiation of human chondrocytes depends on cell microenvironment and serum selection. Cells 8, E934 (2019).

33. Li, Y. F. et al. Levels of peripheral Th17 cells and serum Th17-related cytokines in patients with multiple sclerosis: a meta-analysis. Mult. Scler. Relat. Disord. 18 20-25 (2017).

34. Mei, Y. et al. Increased serum IL-17 and IL-23 in the patient with ankylosing spondylitis. Clin. Rheumatol. 30, 269-273 (2011).

35. Yazici, C., Kose, K., Calis, M., Kuzuguden, S. \& Kirnap, M. Protein oxidation status in patients with ankylosing spondylitis. Rheumatology 43, 1235-1239 (2004).

36. Cristani, $M$. et al. Circulating advanced oxidation protein products as oxidative stress biomarkers and progression mediators in pathological conditions related to inflammation and immune dysregulation. Curr. Med. Chem. 23 3862-3882 (2016).

37. Mittal, M., Siddiqui, M. R., Tran, K., Reddy, S. P. \& Malik, A. B. Reactive oxygen species in inflammation and tissue injury. Antioxid. Redox Signal. 20, 1126-1167 (2014).

38. Ho, K. J., Chen, P. Q., Chang, C. Y. \& Lu, F. J. The oxidative metabolism of circulating phagocytes in ankylosing spondylitis: determination by whole blood chemiluminescence. Ann. Rheum. Dis. 59, 338-341 (2000).

39. Sheu, S. Y., Tsuang, Y. H., Hsu, F. L., Lu, F. J. \& Chiang, H. C. Superoxide anion scavenge effect of Quercus glauca Thunb. in whole blood of patients with ankylosing spondylitis. Am. J. Chin. Med. 25, 307-315 (1997).

40. Reuter, S., Gupta, S. C., Chaturvedi, M. M. \& Aggarwal, B. B. Oxidative stress, inflammation, and cancer: how are they linked? Free Radic. Biol. Med. 49 1603-1616 (2010).

41. Stanek, A., Cholewka, A., Wielkoszyński, T., Romuk, E. \& Sieroń, A. Decreased oxidative stress in male patients with active phase ankylosing spondylitis who underwent whole-body cryotherapy in closed cryochamber. Oxid. Med. Cell. Longev. 2018, 7365490 (2018).

42. Kataoka, M., Tonooka, K., Ando, T., Imai, K. \& Aimoto, T. Hydroxyl radical scavenging activity of nonsteroidal anti-inflammatory drugs. Free Radic. Res. 27, 419-427 (1997).

43. Couto, D. et al. Scavenging of reactive oxygen and nitrogen species by the prodrug sulfasalazine and its metabolites 5-aminosalicylic acid and sulfapyridine. Redox Rep. 15, 259-267 (2010).

44. Kim, E. K. et al. IL-17-mediated mitochondrial dysfunction impairs apoptosis in rheumatoid arthritis synovial fibroblasts through activation of autophagy. Cell Death Dis. 8, e2565 (2017).

45. Novak, E. A. \& Mollen, K. P. Mitochondrial dysfunction in inflammatory bowel disease. Front. Cell Dev. Biol. 3, 62 (2015).
46. Lee, Y. H. \& Song, G. G. Meta-analysis of differentially expressed genes in ankylosing spondylitis. Genet. Mol. Res. 14, 5161-5170 (2015).

47. Gu, X., Liu, C. J. \& Wei, J. J. Predicting pathway cross-talks in ankylosing spondylitis through investigating the interactions among pathways. Braz. J. Med. Biol. Res. 51, e6698 (2017)

48. van der Heijde, D. et al. Tofacitinib in patients with ankylosing spondylitis: a phase II, 16-week, randomised, placebo-controlled, dose-ranging study. Ann. Rheum. Dis. 76, 1340-1347 (2017).

49. van der Heijde, D. et al. Efficacy and safety of filgotinib, a selective Janus kinase 1 inhibitor, in patients with active ankylosing spondylitis (TORTUGA): results from a randomised, placebo-controlled, phase 2 trial. Lancet 392, 2378-2387 (2018).

50. Letts, J. A. \& Sazanov, L. A. Clarifying the supercomplex: the higher-order organization of the mitochondrial electron transport chain. Nat. Struct. Mol. Biol. 24, 800-808 (2017)

51. Cadenas, E. \& Davies, K. J. Mitochondrial free radical generation, oxidative stress, and aging. Free Radic. Biol. Med. 29, 222-230 (2000).

52. Cipriani, P. et al. Stem cells in autoimmune diseases: implications for pathogenesis and future trends in therapy. Autoimmun. Rev. 12, 709-716 (2013).

53. Ganguly, P. et al. Age-related changes in bone marrow mesenchymal stromal cells: a potential impact on osteoporosis and osteoarthritis development. Cell Transplant. 26, 1520-1529 (2017)

54. Bollow, M. et al. Quantitative analyses of sacroiliac biopsies in spondyloarthropathies: $T$ cells and macrophages predominate in early and active sacroiliitis - cellularity correlates with the degree of enhancement detected by magnetic resonance imaging. Ann. Rheum. Dis. 59, 135-140 (2000).

55. Zeng, L., Lindstrom, M. J. \& Smith, J. A. Ankylosing spondylitis macrophage production of higher levels of interleukin-23 in response to lipopolysaccharide without induction of a significant unfolded protein response. Arthritis Rheum 63, 3807-3817 (2011).

56. Cho, D. I. et al. Mesenchymal stem cells reciprocally regulate the M1/M2 balance in mouse bone marrow-derived macrophages. Exp. Mol. Med. 46, e70 (2014).

57. Ghannam, S., Pene, J., Moquet-Torcy, G., Jorgensen, C. \& Yssel, H. Mesenchymal stem cells inhibit human Th17 cell differentiation and function and induce a $T$ regulatory cell phenotype. J. Immunol. 185, 302-312 (2010).

58. Luz-Crawford, P. et al. Mesenchymal stem cells generate a CD4+CD25+Foxp3 + regulatory $T$ cell population during the differentiation process of Th1 and Th17 cells. Stem Cell Res. Ther. 4, 65 (2013).

59. Przepiera-Będzak, H., Fischer, K. \& Brzosko, M. Serum IL-6 and IL-23 levels and their correlation with angiogenic cytokines and disease activity in ankylosing spondylitis, psoriatic arthritis, and SAPHO syndrome. Mediators Inflamm. 2015 785705 (2015).

60. Ranganathan, $V$. et al. Macrophage migration inhibitory factor induces inflammation and predicts spinal progression in ankylosing spondylitis. Arthritis Rheumatol. 69, 1796-1806 (2017)

61. Xie, Z. et al. MCP1 triggers monocyte dysfunctions during abnormal osteogenic differentiation of mesenchymal stem cells in ankylosing spondylitis. J. Mol. Med. 95, 143-154 (2017).

62. Becher, B., Tuques, S. \& Greter, M. GM-CSF: from growth factor to central mediator of tissue inflammation. Immunity 45, 963-973 (2016).

63. Regmi, S., Pathak, S., Kim, J. O., Yong, C. S. \& Jeong, J. H. Mesenchymal stem cell therapy for the treatment of inflammatory diseases: challenges, opportunities, and future perspectives. Eur. J. Cell. Biol. 98, 151041 (2019).

64. Wang, D. et al. Umbilical cord mesenchymal stem cell transplantation in active and refractory systemic lupus erythematosus: a multicenter clinical study. Arthritis Res. Ther. 16, R79 (2014). 